\title{
Satellites for supply-side water balancing
}

\author{
To highlight vulnerabilities of future food production under climate change, we need a better understanding of crop \\ yield variability drivers. Soil moisture, which plays interdependent roles in water demand and supply, determined \\ from satellite observations can markedly improve the predictive skill of US maize yield models.
}

\section{Michelle Tigchelaar}

M eeting the food needs of a growing world population in a changing climate is a complex challenge ${ }^{1}$. Beyond human behaviour and technological interventions, crop production is driven by an interdependent set of environmental variables that are in rapid flux — sunlight, heat, humidity, soil moisture and nutrients. This adds great complexity to our understanding of the impacts of climate change. Writing in Nature Food, Rigden and co-authors ${ }^{2}$ cut through the environmental complexity by utilizing newly available satellite soil moisture data to markedly improve the predictive skill of US maize yield models.

Predicting the response of crop yields to a changing climate typically takes one of two routes: a process-based model, or an empirical one ${ }^{3}$. Process-based models include detailed representations of biophysics but are difficult to implement on a large scale due to the complexity of environmental and management factors involved. Empirical models, on the other hand, are often preferred when using large spatial scales but are more limited in their ability to accurately capture underlying processes. Driven by the ready availability of global and long-term air temperature and rainfall data, empirical models originally used these two variables to represent the key environmental drivers of changes in crop yields.

However, in reality, air temperature and rainfall are only crude proxies of how a plant interacts with its environment ${ }^{4,5}$. Water supply and demand for instance also depend on factors such as runoff, evaporation and groundwater storage. Empirical crop yield models therefore need to include variables that better represent these various plant processes. For water demand, empirical models now use vapour pressure deficit which incorporates measures of humidity - instead of temperature alone ${ }^{6}$. However, advances made in the representation of water supply have been limited by the poor availability and accuracy of large-scale soil moisture data.

With the release of the first data from the Soil Moisture Active Passive (SMAP) satellite ${ }^{7}$, Rigden et al. are able to directly input water supply - in the form of rootzone soil moisture - into empirical models of US maize yield. The first four years of daily data (2015-2018) match well with ground observations and generate much improved model skill relative to the use of rainfall as a proxy for supply.

In both empirical models and flux tower data, Rigden et al. find that the demand and supply of water strongly interact in driving crop yields. That is, while heat stress is often accompanied by water stress, the two types of stress are not interchangeable when predicting yield outcomes. Looking towards the future, this leads to a more nuanced picture than one of simply 'high temperatures are bad'. In fact, projected future losses in US maize yields that include soil moisture data are only about half of what they would be if these interactions are not taken into account ${ }^{8}$. This is because persistent root-zone soil moisture can partially offset the increasing water demand from rising air temperatures.

Furthermore, Rigden et al. re-emphasize the detrimental impacts of cool and wet conditions, which caused half of the total maize yield losses in 2015-2018 and will likely continue to harm crop production, as already evidenced by the spring 2019 floods that decimated crops in the US Midwest ${ }^{9}$. Measures of winter and spring rainfall, including extremes of weather, have not yet been included in empirical models. Doing so could increase estimates of future crop losses but would require creative integration across temporal (from daily extremes to seasons) and spatial (from weather systems to watersheds) scales.

Future work also needs to evaluate whether climate models are up to the task of accurately projecting soil moisture changes, and the approach that would be used. Rigden et al. show a substantial improvement of crop model predictive skill when soil moisture data are included, but this finding may be of limited value when soil moisture in climate models diverges wildly from observations. Improving climate model representation of soil moisture processes is also important given the many feedbacks between soil moisture and (extreme) temperature and rainfall ${ }^{10}$.

A better understanding of the drivers of crop yield variability is important for highlighting vulnerabilities in future food production and identifying adaptive strategies. Here, Rigden et al. share important new insights into the competition between water demand and supply. Their work provides a valuable framework for highlighting the vulnerable parts of the world that will face hot/dry or cool/wet scenarios in the future, and emphasizes the need to identify adaptation pathways that balance water supply and demand. Finally, they serve us a timely reminder that the SMAP satellite data are here - and ready to use.

Michelle Tigchelaar (D)

Center for Ocean Solutions, Stanford University, Stanford, CA, USA.

e-mail:mtigch@stanford.edu

Published online: 18 February 2020 https://doi.org/10.1038/s43016-020-0036-7

\footnotetext{
References

1. Porter, J. R. et al. in Climate Change 2014: Impacts, Adaptation, and Vulnerability (eds Field, C. B. et al.) 485-533 (IPCC, Cambridge Univ. Press, 2014).

2. Rigden, A. J. et al. Nat. Food https://doi.org/10.1038/s43016-0200028-7 (2020).

3. Lobell, D. B. \& Asseng, S. Environ. Res. Lett. 12, 015001 (2017).

4. Hsiao, J., Swann, A. L. S. \& Kim, S.-H. Agric. For. Meteorol. 279, 107692 (2019).

5. Roberts, M. J., Schlenker, W. \& Eyer, J. Am. J. Agric. Econ. 95, 236-243 (2013).

6. Urban, D. W., Sheffield, J. \& Lobell, D. B. Environ. Res. Lett. 10 045003 (2015).

7. Entekhabi, D. et al. Proc. IEEE 98, 704-716 (2010).

8. Zhao, C. et al. Proc. Natl Acad. Sci. USA 114, 9326-9331 (2017).

9. Schwartz, J. A wet year causes farm woes far beyond the floodplains. The New York Times (21 November 2019).

10. Seneviratne, S. I. et al. Earth Sci. Rev. 99, 125-161 (2010).
} 